\title{
COMPOSTOS BIOATIVOS NAS AMÊNDOAS DE MONGUBA
}

\author{
,A.M.M. SILVA ${ }^{1}$, A. E. G. AMARAL ${ }^{1}$, E. V. S. C. BRAGA ${ }^{2}$, P. H. M. SOUSA ${ }^{2}$ \\ R.W. FIGUEIREDO ${ }^{1}$ \\ ${ }^{1}$ Universidade Federal do Ceará, Departamento de Tecnologia de Alimentos \\ ${ }^{2}$ Universidade Federal do Ceará, Instituto de Cultura e Arte \\ E-mail para contato: $\underline{\text { aurenicemota@gmail.com }}$
}

\begin{abstract}
RESUMO - A mongubeira (Pachira aquática aublet) é uma planta nativa do sul do México que se adaptou aos diversos tipos de solos brasileiros, sendo muito utilizada na ornamentação urbana de muitas cidades do país. Os compostos bioativos, muito presente em frutos, exibem propriedades antioxidantes além de estarem associados a diversos benefícios físicos. Devido a escassez de informações sobre os teores de compostos bioativos nas sementes de monguba, o presente trabalho objetivou avaliar os teores de antocianinas, flavonóides amarelos, e os carotenóides: licopeno e $\beta$-caroteno nas amêndoas da monguba.Assim, os bioativos foram determinados por espectrofotometria. As amêndoas de mongubaapresentaram, $795 \pm 0,41 \mu \mathrm{g}$ de antocianinas por $100 \mathrm{~g}$ amêndoa, 27, $644 \mu \mathrm{g}$ de flavonóides amarelos $/ 100 \mathrm{~g}$. Os teores de licopeno e B-caroteno também foram considerados baixos, sendo de $0,09 \mu \mathrm{g} / 100 \mathrm{~g}$ para ambos. A presença de antocianinas, flavonóides e carotenóides faz desse fruto uma fonte de bioativos, contribuindo para uma dieta variada e benéfica para o organismo.
\end{abstract}

\section{INTRODUÇÃO}

Pachira aquática aublet (Bombacaceae) é uma espécie nativa do Sul do México até o Norte da América do Sul (OLIVEIRA et al., 2000). Na região amazônica, essas plantas ocorrem predominantemente em terrenos sujeitos a inundações periódicas, especialmente, nas margens de rios e córregos (PEIXOTO; ESCUDEIRO, 2002). Popularmente, é conhecida por Monguba,Mamorana, Munguba, Castanheira do Maranhão, Cacau Selvagem, Cacau Falso ou Castanhola (SOUZA; LORENZI, 2008).

Esta espécie é bastante utilizada como ornamental, segundo LORENZI (1992), a Pachira aquática aublet foi introduzida em arborização urbana na segunda metade do século XIX pelo botânico e paisagista francês Glaziou, na fabricação de cordas, flechas, enchimentos para colchões e travesseiros (SOUZA; LORENZI, 2008). Suas sementes são utilizadas no setor alimentício como fonte de proteínas e na produção de óleos e purgantes (PEIXOTO; ESCUDEIRO, 2002), os frutos são comestíveis e podem ser consumidos de diversas maneiras: crus, assados, cozidos ou torrados e transformados em farinha. Segundo Cetto e Heinrich (2005), o consumo de Pachira aquática aublet pode ter efeito hipoglicemiante no tratamento de diabetes e seus sintomas.

Os compostos bioativos presentes nos alimentos podem agir de diferentes formas, tanto no que se refere aos alvos fisiológicos como aos seus mecanismos de ação. A ação antioxidante, comum nesses compostos, por exemplo, deve-se ao potencial de óxidoredução de determinadas moléculas, à capacidade dessas moléculas em competir por 
sítios ativos e receptores nas diversas estruturas celulares ou, ainda, à modulação da expressão de genes que codificam proteínas envolvidas em mecanismos intracelulares de defesa contra processos oxidativos degenerativos de estruturas celulares (DNA, membranas)(BASTOS et al., 2009).

Dentre os compostos fenólicos com propriedade antioxidante, destacam-se os flavonóides quequimicamente, englobam as antocianinas e os flavonóis.As antocianinas são pigmentos solúveis em água,amplamente difundidas no reino vegetal e conferem as várias nuanças de cores entre laranja, vermelha e azulencontradas em frutas, vegetais, flores, folhas e raízes (FRANCIS ${ }^{\mathrm{b}}, 1989$ ). Os flavonóis são pigmentos de coresbranca ou amarelo claro encontrados nesses alimentos.Os últimos pigmentos citados são importantes por atuarem na co-pigmentação das antocianinas (BOBBIO \&BOBBIO,1995). Atualmente, existe uma tendência mundialem usar pigmentos naturais como corantes paraalimentos e entre eles destacam-se as antocianinas. Esse interesse é também influenciado pelas observaçõespromissoras de seu potencial benéfico à saúde decorrente de sua ação antioxidante (ESPÍN et al., 2000; WANGet al., 1997).

Os carotenóides são corantes naturais presentes nas frutas e vegetais (cenouras, tomates, espinafre, laranjas, pêssegos, entre outros), sendo que sua estrutura química é composta por ligações duplas conjugadas, que são responsáveis por sua cor e por algumas de suas funções biológicas (SIES; STAHL, 1995).

O beta-caroteno é o carotenóide pró-vitamina A mais ativo. Ele é um pigmento laranja termolábil, sensível à luz e ao oxigênio, e que está associado à proteção contra doenças cardíacas e câncer (CARVALHO et al., 2006; CARPER,1995).

O licopeno é um pigmento vermelho que ocorre naturalmente apenas em tecidos de hortaliças e algas. Ele é encontrado em elevada concentração em tomate e seus produtos derivados, sendo o antioxidante mais eficiente dentre todos os carotenóides testados - o dobro da atividade do beta-caroteno(CLINTON, 1998; SHIet al., 1999). Estudos de Carvalho (2006) mostram que o licopeno na dieta está relacionado à redução da incidência de certos tipos de câncer e o seu nível no tecido adiposo foi relacionado à redução do risco de ataque cardíaco.

Devido à escassez de informações sobre os teores de compostos bioativos nas sementes de Monguba, o presente trabalho objetivou avaliar os teores de antocianinas, flavonóides amarelos e os carotenóides: licopeno e $\beta$-caroteno nas amêndoas da Monguba.

\section{MATERIAL E MÉTODOS}

\subsection{Sementes de Monguba}

Amostras de sementes maduras de Pachira aquática aubletforam obtidos a partir de plantas que cresceram naturalmente no solo do Campus do Pici da Universidade Federa do Ceará.

\subsection{Quantificação de Antocianinas e Flavonóides}


A quantificação dos teores de antocianinas e de flavonóides amarelos nas amêndoas de Monguba ocorreu segundo a Francis ${ }^{\mathrm{a}}$ (AcademicPress,1982) com algumas adaptações. Onde, a $1 \mathrm{~g}$ de cada amostra foram adicionados $10 \mathrm{~mL}$ de solução extratora ( $\mathrm{HCl}$ e etanol). A solução foi agitada por 3 minutos em seguida foi armazenado em geladeira por 16 horas. Após esse período, as amostras foram filtradas. Logo após a filtração, foi realizada leitura da absorbância do filtrado em espectrofotômetro com comprimento de onda de $535 \mathrm{~nm}$ para quantificação de antocianinas, e $347 \mathrm{~nm}$ para a quantificação de flavonóides. Todo o procedimento foi realizado em triplicata.

\subsection{Quantificação dos Carotenóides ( $\beta$-caroteno e licopeno)}

Ocorreu segundo método descrito por NAGATA; YAMASHITA (1992) com algumas adaptações. No qual foi adicionado $10 \mathrm{~mL}$ da solução extratora de acetonahexano (4:6) em um grama de amostra, a mistura é agitada por um minuto e filtrada. $\mathrm{O}$ filtrado foi então recolhido para leitura em espectrofotômetro nos comprimentos de onda de $453 \mathrm{~nm}, 505 \mathrm{~nm}, 645 \mathrm{~nm}$ e $663 \mathrm{~nm}$. Todo o procedimento foi realizado em triplicata.

\section{RESULTADOS E DISCUSSÃO}

Os teores encontrados estão expressos na tabela 1, onde podemos observar que o biocomposto de maior quantidade encontrado foram os flavonóides amarelos, seguido das antocianinas, e licopeno e $\beta$-caroteno que apresentaram resultados semelhantes.

Tabela 1 - Teores de compostos bioativos nas amêndoas de Monguba

\begin{tabular}{cccc}
\hline Antocianinas & Flavonóides amarelos & Licopeno & $\beta$-caroteno \\
\hline $7,795 \pm 0,41$ & $27,644 \pm 3,71$ & $0,09 \pm$ & 0,0955 \\
$\mathrm{mg} / 100 \mathrm{~g}$ & $\mathrm{mg} / 100 \mathrm{~g}$ & $0,003 \mathrm{mg} / 100 \mathrm{~g}$ & $\pm 0,002 \mathrm{mg} / 100 \mathrm{~g}$ \\
\hline
\end{tabular}

Resultados apresentados como Média \pm Desvio padrão

As sementes de Monguba apresentaram baixos teores de flavonóides, se comparada com as sementes de abacate, 48mg/100g, segundo pesquisa de Lemos (2008). Entretanto, os valores de flavonóides encontrados representamaproximadamente $40 \%$ da ingestão diária sugerida para mulheres e $30 \%$ da ingestão sugerida para homens, (PAULI, 2010). Podendo ser considerada a amêndoa de Monguba como um alimento rico em flavonóides.

$\mathrm{Na}$ tabela de Ingestão Diária Recomendada para Adultos disponibilizada pela ANVISA, recomenda-se a ingestão de $1 \mu \mathrm{g}$ de $\beta$-caroteno, comparando com os resultados encontrados para as sementes de Monguba, podemos inferir que em $25 \mathrm{~g}$ da mesma contem pouco mais que o suficiente que o individuo precisa. Sendo considerada a amêndoa de Monguba como um alimento fonte de $\beta$-caroteno, de acordo com a descrição dos termos usados para alimentos segundo a Portaria $n^{\circ} 27$ (ANVISA, 1998). A Monguba também supera outras espécies tropicais como Mulungu (ErythrinavelutinaWilld.) e Jucá (Caesalpiniaferrea Mart. ex. Tull) que são fontes escassas de carotenóides(JUNIOR et al., 2011). Entretanto, esses valores são baixos se 
comparados com os teores relatados por Lemos (2008) em diferentes genótipos de sementes de Urucum (BixaorellanaL), que variaram entre 3,79 e 12,60 $\mathrm{mg} \mathrm{g}^{-1}$.

Os resultados obtidos para licopeno nas amêndoas de Monguba $(0,09 \mathrm{mg} / 100 \mathrm{~g}) \mathrm{a}$ apontam como uma semente escassa em licopeno, e por esse motivo não se pode dizer que a ingestão de Monguba implicará em benefícios clínicos relacionados ao licopeno (CARVALHO, 2006).

O teor de antocianinas $(7,79 \mathrm{mg} / 100 \mathrm{~g})$ nas amêndoas de monguba foi superior aos 0,6 $\mathrm{mg} / 100 \mathrm{~g}$ determinado em amêndoas de Baru (Dipteryxvog) por Lemos (2012) em sua pesquisa. As sementes de Monguba se destacam como fontes de antocianinas se comparada às outras sementes como a semente de Abacate $(0,003 \mathrm{mg} / 100 \mathrm{~g})$ e de Urucum (PESSOA, 2012 e LEMOS, 2008 ). A Monguba é uma fonte rica em antocianinas, uma vez que são considerados frutos ricos em antocianinas aqueles que apresentam mais do que $2 \mathrm{mg}$ de antocianinas. $100 \mathrm{~g}^{-1}$ do fruto (MACHEIX; FLEURIET; BILLOT, 1990).

\section{CONCLUSÃO}

A Monguba se apresentou como boa fonte de antocianinas e flavonóides. A presença de licopeno e $\beta$-caroteno nas amêndoas de Monguba, mesmo em pequenas quantidades,torna o consumo desse fruto interessante, uma vez que a presença de bioativos contribui para benefícios à saúde do organismo tais como atividade antioxidante.

\section{REFERÊNCIAS BIBLIOGRÁFICAS}

BASTOS, D. H. M.; ROGERO, M. M.;Arêas, J. A. G. Mecanismos de ação de compostos bioativos dos alimentos no contexto de processos inflamatórios relacionados à obesidade.ArqBrasEndocrinolMetab. v. 53, n. 5, p. 647, 2009.

BOBBIO, P.A.; BOBBIO, F.O. Introdução à Química de alimentos. 2.ed.São Paulo: Varela, 1995. 223p.

BRASIL. Ministério da Saúde. Secretaria da Vigilância Sanitária. Portaria n ${ }^{\circ} 27$; Regulamento Técnico referente à Informação Nutricional Complementar (declarações relacionadas ao conteúdo de nutrientes), constantesdoanexo desta Portaria. 13 jan de 1998.

BRASIL. Ministério da Saúde. Secretaria da Vigilância Sanitária. RDC n 269; Regulamento Técnico sobre a ingestão diária recomendada (IDR) de proteína, vitaminas e minerais. 22 set de 2005.

CARVALHO PGB; MACHADO CMM; MORETTI CL; FONSECA, ME N. Hortaliças como alimentos funcionais.Hortic. bras., v. 24, n. 4, p. 400, out.-dez. 2006.

CARPER J. Alimentos: o melhor remédio para aboa saúde. 1995. Rio de Janeiro: Ed. Campus.632p. 
CETTO, A.A.; HEINRICH, M.Mexican plants with hypoglycaemic effect used in the treatment of diabetes.Journal of Ethnopharmacology, v.99, p. 325-348, 2005.

CLINTON SK.. Lycopene: chemistry, biology, and implications for human health anddisease. Nutrition Reviews, v.56, p. 35-51, 1998.

ESPÕN, J.C.; SOLER-RIVAS, C.; WICHERS, H.J.; GARCÕA-VIGUERA, C. Anthocyanin-based natural colorants: a new source of antiradical activityfor foodstuff. Journal of Agricultural and Food Chemistry, v.48, p. 1588-1592, 2000.

${ }^{a}$ FRANCIS, F.J. Analysis of anthocyanins. In: MARKAKIS, P. (ed.). Anthocyaninsasfood colors.Academic Press.New York, p. 181-207, 1982.

${ }^{\mathrm{b}}$ FRANCIS, F.J. Food colorants: anthocyanins. Critical Reviews in Food Science and Nutrition,v.28, p. 273-314, 1989.

JUNIOR, N. O. R.; FERNANDEZ, L. G.; CASTRO, R. D.; SILVA, L. C.; GUALBERTO, S. A.; PEREIRA, M. L. A.; SILVA, M. V. Compostos bioativos e atividade antioxidante deextratos brutos de espécies vegetais da caatinga. Braz. J. FoodTechnol., Campinas, v. 14, n. 1, p. 50-57, 2011.

LEMOS, A. R. Caracterização físico-química, bioquímica eAvaliação da atividade antioxidante emGenótipos de urucueiros (Bixaorellana 1.). Dissertação. Universidade Estadualdo Sudoeste da Bahia. 2008.

LEMOS, M. R. B. Caracterização e estabilidade dos compostos bioativos em amendoas de Baru (Dipteryxalata Vog.), submetidos a processo de torrefação. Dissertação. Universidade de Brasília, 2012.

MACHEIX, J. J.; FLEURIET, A.; BILLOT, J. FruitsPhenolics. Boca Raton: CRC Press, 1990.

NAGATA, M.; YAMASHITA, I. Simplemethod for simultaneous determinationof chlorophyll and carotenoids in tomato fruit. J. Japan. Soc. Food Sci. Technol., v.39, n. 10, p. 925-928, 1992.

OLIVEIRA, J. T. A. et al. Composition and nutritional properties of seeds from Pachiraaquatic Aubl., SterculiastriataSt Hil et Naud and TerminaliacatappaLinn.

Food Chemistry, v.70, n.2, p.185-191, 2000.

PEIXOTO, A. L.; ESCUDEIRO, A. Pachiraaquática (Bombacaceae) na obra "História dos animais e árvores do Maranhão" de Frei Cristóvão de Lisboa. Rodriguésia, v. 53, n. 82, p.123-130, 2002.

SHI J; MAGUER ML; KAKUDA Y; LIPTAY A;NIEKAMP F.Lycopene degradation and isomerization in tomato dehydration. Food Research International, v.32, p. 15-21, 1999.

SOUZA, V. C.; LORENZI, H. Botânica sistemática: guia ilustrado para identificação das famílias de Fanerógamas nativas e exóticas no Brasil, baseado em APG II. 2. ed.Nova Odessa, SP: InstitutoPlantarum, 2008. 704p. 
WANG, H.; CAO, G.; PRIOR, R. L. Oxigen radical absorbing capacity of anthocyanins.Journal of Agricultural and Food Chemistry, v.45, p.304-309, 1997. 